\title{
Cangrelor or Clopidogrel in Patients with Type 2 Diabetes Mellitus Undergoing Percutaneous Coronary Intervention: A Meta-Analysis of Randomized Controlled Trials
}

\author{
Hongtao Lu • Wenjun Guan · Yanhua Zhou · Zhangui Tang • \\ Hong Bao
}

Received: February 5, 2019 / Published online: March 23, 2019

(c) The Author(s) 2019

\section{ABSTRACT}

Introduction: With recent advances in interventional cardiology where percutaneous coronary intervention (PCI) has become the most preferred invasive strategy and with advances in adjunctive pharmacotherapy, several newer oral $\mathrm{P}_{2} \mathrm{Y}_{12}$ inhibitors have reached the market. In this analysis, we aimed to compare the cardiovascular outcomes and bleeding events which

Hongtao Lu and Wenjun Guan have contributed equally to this study as co-first authors.

Enhanced digital features To view enhanced digital features for this article go to https://doi.org/10.6084/ m9.figshare.7777169.

H. Lu · W. Guan

Jingzhou Central Hospital of Cardiology, The Second Clinical Medical College, Yangtze University, Jingzhou, Hubei, People's Republic of China

\section{Y. Zhou}

Department of Hematology, Jingzhou First People's Hospital, The First Affiliated Hospital of Yangtze

University, Jingzhou, People's Republic of China

Z. Tang

Institute of Cardiovascular Disease, Xiangya

Hospital, Central South University, Changsha,

Hunan, People's Republic of China

\section{H. Bao $(\square)$}

Jiangling County People's Hospital of Cardiology, Jingzhou, Hubei, People's Republic of China e-mail: jzszxyyxnk@163.com were associated with the use of cangrelor versus clopidogrel in patients with type 2 diabetes mellitus (T2DM) $48 \mathrm{~h}$ after PCI.

Methods: The electronic databases MEDLINE (PubMed), www.ClinicalTrials.gov, EMBASE, and Cochrane central were searched for relevant publications comparing canagrelor with clopidogrel during PCI. Patients with T2DM were extracted. Adverse cardiovascular outcomes and bleeding events at $48 \mathrm{~h}$ follow-up were considered as the end points. This meta-analysis was carried out with the latest RevMan software (5.30). Odds ratios (OR) and 95\% confidence intervals (CI) were used to represent the data.

Results: This analysis consisted of a total number of 5031 participants with T2DM (enrolled between the years 2006 and 2012). Compared to clopidgrel, use of cangrelor in these patients with T2DM was not associated with significantly different primary end point (OR 0.94, 95\% CI $0.75-1.16 ; \quad P=0.55$ ), myocardial infarction (OR 0.96, 95\% CI 0.76-1.20; $P=0.71$ ), all-cause death (OR 0.70, 95\% CI 0.25-1.96; $P=0.49$ ), ischemia-driven revascularization (OR 0.66, 95\% CI 0.32-1.36; $P=0.26$ ), and stent thrombosis (OR $0.45,95 \%$ CI $0.17-1.17 ; \quad P=0.10)$. Thrombolysis in myocardial infarction (TIMI)-defined major and minor bleedings were similarly manifested: (OR 1.02, 95\% CI 0.38-2.74; $P=0.96$ ) and (OR 1.39, 95\% CI 0.70-2.79; $P=0.35$ ), respectively. Global use of strategies to open occluded arteries (GUSTO)-defined moderate and severe bleeding 
were also not significantly different: (OR 1.36, 95\% CI $0.70-2.67 ; P=0.37$ ) and (OR 1.21, 95\% CI 0.41-3.59; $P=0.74$ ), respectively. However, GUSTO-defined mild bleeding and acute catheterization and urgent intervention triage strategy (ACUITY)-defined major and minor bleedings were significantly in favor of clopidogrel in comparison to cangrelor in these patients with T2DM: (OR 1.28, 95\% CI $1.09-1.50 ; \quad P=0.003), \quad(\mathrm{OR} \quad 1.43, \quad 95 \% \quad \mathrm{CI}$ $1.05-1.94 ; P=0.02)$, and (OR 1.23, 95\% CI 1.04-1.46; $P=0.02$ ), respectively. Other bleeding outcomes were not significantly different.

Conclusions: In these patients with T2DM, cangrelor was comparable to clopidogrel in terms of efficacy at $48 \mathrm{~h}$ following PCI. However, it was associated with significantly higher mild GUSTO bleeding and major and minor ACUITY bleeding, therefore requiring further workups on its safety side. This hypothesis should be explored further and confirmed in other forthcoming trials based strictly on patients with T2DM.

Keywords: Antiplatelet agents; Cangrelor; Cardiovascular disease; Clopidogrel; Percutaneous coronary intervention; Type 2 diabetes mellitus

$\begin{array}{ll}\text { Abbreviations } \\ \text { FDA } & \text { Food and Drug Administration } \\ \text { PCI } & \text { Percutaneous coronary intervention } \\ \text { T2DM } & \text { Type } 2 \text { diabetes mellitus }\end{array}$

\section{INTRODUCTION}

The co-existence of type 2 diabetes mellitus (T2DM) and cardiovascular diseases has contributed to the annual increased number of percutaneous coronary interventions (PCI). With recent advances in interventional cardiology where PCI has become among the most preferred invasive strategy for majority of the patients, and with advances in adjunctive pharmacotherapy, several newer oral $\mathrm{P}_{2} \mathrm{Y}_{12}$ inhibitors have reached the market [1].

Cangrelor is one of the $\mathrm{P}_{2} \mathrm{Y}_{12}$ inhibitors which have been approved for use by the Food and Drug Administration (FDA) since June 2015 [2]. In contrast to the other $\mathrm{P}_{2} \mathrm{Y}_{12}$ inhibitors, this drug is available in intravenous form and has been administered along with aspirin or in combination with clopidogrel during coronary stent implantation [3].

The CHAMPION PCI [4], CHAMPION PHOENIX [5], and CHAMPION PLATFORM [6] trials were set up to study the potential effects of cangrelor during PCI. However, despite of the inclusion of a large number of patients with T2DM in those trials, the trials were based on the general population with cardiovascular diseases. There was no research based specifically on the use of cangrelor in T2DM participants with coronary heart disease undergoing PCI.

In this analysis, we aimed to compare the cardiovascular outcomes and bleeding events which were associated with the use of cangrelor versus clopidogrel in patients with T2DM $48 \mathrm{~h}$ after PCI.

\section{METHODS}

\section{Electronic Databases}

The electronic databases MEDLINE (PubMed), www.ClinicalTrials.gov, EMBASE, and Cochrane central were searched for relevant publications comparing canagrelor with clopidogrel in the general population undergoing PCI.

\section{Search Terms/Phrases and Mode of Search}

The aforementioned electronic databases were searched for English-language publications using the following common terms/phrases:

- Cangrelor, clopidogrel and percutaneous coronary intervention/PCI

- Cangrelor, clopidogrel and diabetes mellitus

- Newer antiplatelets and percutaneous coronary intervention/PCI

- Cangrelor, clopidogrel and coronary angioplasty

- Cangrelor and diabetes mellitus

After selecting relevant publications, the authors went through the list of references to search for additional relevant articles. 


\section{Inclusion and Exclusion Criteria}

The inclusion criteria were as follows:

- Randomized controlled trials comparing cangrelor versus clopidogrel in patients undergoing PCI

- Trials which also included patients with T2DM

- Trials whereby efficacy and bleeding outcomes were reported

- Trials that reported outcomes at $48 \mathrm{~h}$ after PCI

The exclusion criteria were as follows:

- Observational studies (retrospective and prospective studies, reports, case studies)

- Meta-analyses and literature reviews as well as systematic reviews

- Studies that did not include participants with T2DM for extraction

- Studies that did not report the expected efficacy and bleeding events

- Repeated studies

\section{Data Extraction and Quality Assessment}

Five authors were involved in the whole data extraction process. First of all the number of patients with T2DM was extracted from each trial followed by the total number of events representing each outcome. Then other features including the type of participants, the baseline features, and the methodological quality of each trial were extracted. Any disagreement which was encountered was resolved by contacting and discussing with the corresponding author.

The methodological quality of the trials was assessed on the basis of the criteria recommended by the Cochrane Collaboration (low, moderate, or high risk bias) [7].

\section{Statistical Analysis}

This meta-analysis was carried out with the latest RevMan software (5.30). Odds ratios (OR) and $95 \%$ confidence intervals (CI) were used to represent the data.

Heterogeneity was assessed by the Q statistic test $(P<0.05$ was considered statistically significant) and the $I^{2}$ statistic test (greater the $I^{2}$ value, greater the heterogeneity).

A fixed-effect statistical model was used.

Sensitivity analysis was carried out by a method of exclusion whereby each trial was excluded one by one and a new analysis was carried out each time to note any significant deviation from the main result.

Publication bias was visually assessed by observing funnel plots.

\section{Compliance with Ethics Guidelines}

Since in this analysis, no experiment was carried out using human or animal by any of the authors, ethical approval or board review approval was not required.

\section{RESULTS}

\section{Search Outcomes}

A total number of 465 publications were searched with reference to the PRISMA guideline [8]. On the basis of an assessment of the titles and abstracts, 418 publications were eliminated since they did not meet the requirements of the current article.

Forty-seven full-text articles were assessed for eligibility.

Further articles were eliminated on the basis of the following criteria: meta-analyses (11), literature reviews (3), pooled analyses (7), did not report the relevant outcomes (3), observational cohorts (2), duplicated studies (18).

Finally only three trials [4-6] satisfied the inclusion and exclusion criteria and were selected for this analysis as demonstrated in Fig. 1.

\section{General Properties of the Trials}

The general properties of the trials are listed in Table 1. This analysis consisted of a total number of 5031 participants with T2DM (enrolled between the years 2006 and 2012) who underwent coronary angioplasty. Those patients were 


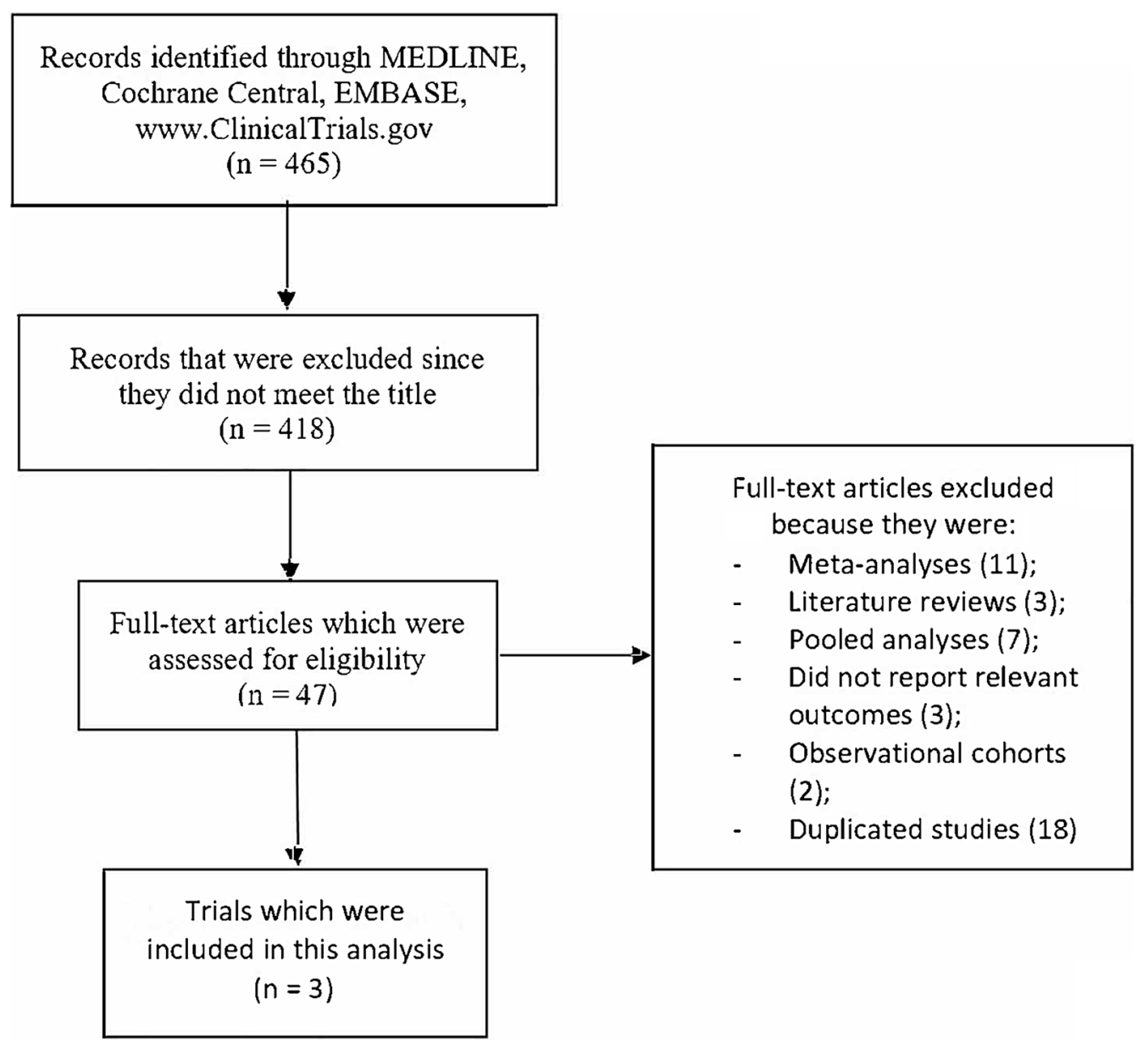

Fig. 1 Flow diagram to represent the study selection

extracted from the general population undergoing PCI. A detailed list is shown in Table 1.

After methodological quality assessment, the trials were judged to have reported low to moderate risk of bias based on the criteria set up by the Cochrane Collaboration.

\section{Outcomes Reported in Each Trial}

During the data extraction process, outcomes were separately extracted and studied for their presence in the other trials.

The outcomes reported by the trials are listed below and in Table 2 .

The outcomes were as follows:

- Primary end points including composites of death, myocardial infarction (MI), ischemia- driven revascularization, and/or stent thrombosis

- MI

- Death of any cause

- Ischemia-driven revascularization

- Stent thrombosis

- Access site bleeding requiring radiological or surgical intervention

- Hematoma at puncture site $\leq 5 \mathrm{~cm}$ or $>5 \mathrm{~cm}$

- Intracranial hemorrhage

- Intraocular hemorrhage

- Bleeding requiring surgery

- Retroperitoneal hemorrhage

- Ecchymosis

- Epistaxis

- Oozing at puncture site

- Thrombocytopenia 
Table 1 General properties of the trials which were included in this analysis

\begin{tabular}{lllll}
\hline Trials & $\begin{array}{l}\text { Time period of } \\
\text { patients' enrollment }\end{array}$ & $\begin{array}{l}\text { No. of T2DM } \\
\text { participants assigned } \\
\text { to cangrelor }(\boldsymbol{n})\end{array}$ & $\begin{array}{l}\text { No. of T2DM } \\
\text { participants assigned } \\
\text { to clopidogrel }(\boldsymbol{n})\end{array}$ & $\begin{array}{l}\text { Total no. of T2DM } \\
\text { participants per trial } \\
(\boldsymbol{n})\end{array}$ \\
\hline $\begin{array}{l}\text { CHAMPION PCI [4] } \\
\text { CHAMPION }\end{array}$ & $2006-2009$ & 1334 & 1331 & 2665 \\
$\begin{array}{l}\text { PHOENIX [5] } \\
\text { CHAMPION }\end{array}$ & $2010-2012$ & 330 & 359 & 689 \\
\begin{tabular}{l} 
PLATFORM [6] \\
\hline
\end{tabular} & & 815 & & 1677 \\
\hline
\end{tabular}

T2DM type 2 diabetes mellitus

- Any blood transfusion

- ACUITY (acute catheterization and urgent intervention triage strategy)-defined minor and major bleeding [9]

- GUSTO (global use of strategies to open occluded arteries) mild, moderate and severe bleeding [9]

- TIMI (thrombolysis in myocardial infarction)-defined major and minor bleeding [9]

The different types of bleeding have been defined [9]. This analysis had a follow-up time period of $48 \mathrm{~h}$ after PCI.

\section{Baseline Features of the Participants}

Table 3 lists the baseline characteristics of the participants with T2DM. A mean age of 62.0-64.0 years was reported among the participants. Male gender varied from $70.4 \%$ to $73.9 \%$. Family history of coronary artery disease varied from $35.9 \%$ to $46.5 \% ; 25.4 \%$ to $31.9 \%$ of the participants were smokers; $5.2 \%$ to $69.4 \%$ of the participants suffered from stable angina as reported in Table 3.

\section{Results of This Analysis}

Compared to clopidgrel, use of cangrelor in these patients with T2DM was not associated with significantly different primary end point (OR 0.94, 95\% CI 0.75-1.16; $P=0.55$ ), MI (OR $0.96,95 \%$ CI $0.76-1.20 ; P=0.71)$, all-cause death (OR 0.70, 95\% CI 0.25-1.96; $P=0.49$ ), ischemia-driven revascularization (OR 0.66,
95\% CI $0.32-1.36 ; P=0.26)$, and stent thrombosis (OR $0.45,95 \%$ CI $0.17-1.17 ; P=0.10$ ) as demonstrated in Fig. 2.

When cangrelor was used in these patients with T2DM in comparison to clopidogrel, TIMIdefined major and minor bleedings were similarly manifested: (OR 1.02, 95\% CI 0.38-2.74; $P=0.96)$ and (OR 1.39, 95\% CI 0.70-2.79; $P=0.35)$, respectively, as shown in Fig. 3 . GUSTO-defined moderate and severe bleeding were also not significantly different: (OR 1.36, 95\% CI $0.70-2.67 ; P=0.37$ ) and (OR 1.21, 95\% CI 0.41-3.59; $P=0.74)$, respectively, as shown in Fig. 3.

However, GUSTO-defined mild bleeding and ACUITY-defined major and minor bleedings were significantly in favor of clopidogrel in comparison to cangrelor in these patients with T2DM: (OR 1.28, 95\% CI 1.09-1.50; $P=0.003$ ), (OR 1.43, 95\% CI 1.05-1.94; $P=0.02)$, and (OR $1.23,95 \%$ CI 1.04-1.46; $P=0.02$ ), respectively, as shown in Fig. 3.

Access site bleeding requiring radiological or surgical intervention (OR 0.68, 95\% CI $0.19-2.43 ; P=0.56)$, hematoma at puncture site $\leq 5 \mathrm{~cm} \quad(\mathrm{OR} \quad 1.21, \quad 95 \% \quad$ CI $\quad 0.86-1.71$; $P=0.28$ ), hematoma at puncture site $>5 \mathrm{~cm}$ (OR 1.26, 95\% CI $0.95-1.68 ; \quad P=0.11$ ), intracranial hemorrhage (OR 1.72, 95\% CI 0.23-13.06; $P=0.60)$, intraocular hemorrhage (OR 3.00, 95\% CI 0.12-73.60; $P=0.50$ ), bleeding requiring surgery $(\mathrm{OR} 1.03,95 \% \mathrm{CI}$ 0.14-7.30; $P=0.98)$, retroperitoneal hemorrhage (OR 1.52, 95\% CI 0.43-5.39; $P=0.52$ ), ecchymosis (OR 1.32, 95\% CI 1.00-1.75; $P=0.05$ ), epistaxis (OR $0.46,95 \%$ CI $0.16-1.33$; 
Table 2 Outcomes which were reported in the trials

\begin{tabular}{|c|c|c|c|}
\hline Trials & Type of participants & Outcomes reported & $\begin{array}{l}\text { Follow- } \\
\text { up time } \\
\text { period }\end{array}$ \\
\hline $\begin{array}{l}\text { CHAMPION } \\
\text { PCI [4] }\end{array}$ & $\begin{array}{l}\text { T2DM patients with and without } \\
\text { STEMI }\end{array}$ & $\begin{array}{l}\text { Primary end point: composite of death, MI, and } \\
\text { revascularization; MI, ischemia-driven } \\
\text { revascularization, death from any cause, stent } \\
\text { thrombosis, stroke, access site bleeding requiring } \\
\text { radiological or surgical intervention, hematoma at } \\
\text { puncture site } \leq 5 \mathrm{~cm} \text { or }>5 \mathrm{~cm} \text {, intracranial } \\
\text { hemorrhage, intraocular hemorrhage, bleeding } \\
\text { requiring surgery, retroperitoneal hemorrhage, } \\
\text { ecchymosis, epistaxis, oozing at puncture site, } \\
\text { thrombocytopenia, any blood transfusion, any } \\
\text { platelet transfusion, ACUITY-defined minor and } \\
\text { major bleeding, GUSTO mild, moderate, and severe } \\
\text { bleeding, TIMI-defined major and minor bleeding }\end{array}$ & $\begin{array}{l}48 \mathrm{~h} \text { after } \\
\text { PCI }\end{array}$ \\
\hline $\begin{array}{l}\text { CHAMPION } \\
\text { PHOENIX } \\
{[5]}\end{array}$ & $\begin{array}{l}\text { T2DM patients with } \\
\text { stable coronary artery disease or } \\
\text { acute coronary syndrome }\end{array}$ & $\begin{array}{l}\text { Primary end point: composite of death, MI, ischemia- } \\
\text { driven revascularization, or stent thrombosis; MI, } \\
\text { stent thrombosis, ischemia-driven revascularization, } \\
\text { death from any cause, non-CABG-related bleeding, } \\
\text { GUSTO-defined mild, moderate, and severe } \\
\text { bleeding, TIMI-defined minor and major bleeding, } \\
\text { ACUITY-defined major bleeding, any blood } \\
\text { transfusion }\end{array}$ & $\begin{array}{l}48 \mathrm{~h} \text { after } \\
\text { PCI }\end{array}$ \\
\hline $\begin{array}{l}\text { CHAMPION } \\
\text { PLATFORM } \\
{[6]}\end{array}$ & $\begin{array}{l}\text { T2DM patients without STEMI or } \\
\text { T2DM patients with } \\
\text { unstable angina }\end{array}$ & $\begin{array}{l}\text { Primary end point: composite of death, MI, and } \\
\text { revascularization; MI, ischemia-driven } \\
\text { revascularization, death from any cause, stent } \\
\text { thrombosis, access site bleeding requiring } \\
\text { radiological or surgical intervention, hematoma at } \\
\text { puncture site: } \leq 5 \mathrm{~cm} \text { or }>5 \mathrm{~cm} \text {, intracranial } \\
\text { hemorrhage, intraocular hemorrhage, bleeding } \\
\text { requiring surgery, retroperitoneal hemorrhage, } \\
\text { ecchymosis, epistaxis, oozing at puncture site, } \\
\text { thrombocytopenia, any blood transfusion, any } \\
\text { platelet transfusion, ACUITY-defined minor and } \\
\text { major bleeding, GUSTO mild, moderate, and severe } \\
\text { bleeding, TIMI-defined major and minor bleeding }\end{array}$ & $\begin{array}{l}48 \mathrm{~h} \text { after } \\
\text { PCI }\end{array}$ \\
\hline
\end{tabular}

$M I$ myocardial infarction, TIMI thrombolysis in myocardial infarction, $C A B G$ coronary artery bypass surgery, $T 2 D M$ type 2 diabetes mellitus, STEMI ST-elevation myocardial infarction, PCI percutaneous coronary intervention, $A C U I T Y$ acute catheterization and urgent intervention triage strategy, GUSTO global use of strategies to open occluded arteries 
Table 3 Baseline features of the participants

\begin{tabular}{llllll}
\hline Trials & Age (years) & Male (\%) & $\begin{array}{l}\text { Family history } \\
\text { of CAD (\%) }\end{array}$ & $\begin{array}{l}\text { Smoking } \\
\text { history (\%) } \\
\text { CA/CL }\end{array}$ & $\begin{array}{l}\text { Stable angina } \\
\text { (\%) } \\
\text { CA/CL }\end{array}$ \\
\hline CHAMPION PCI [4] & $62.0 / 62.0$ & $73.9 / 72.2$ & $45.9 / 46.5$ & $28.5 / 29.1$ & $15.1 / 15.0$ \\
CHAMPION PHOENIX [5] & $64.0 / 64.0$ & $72.5 / 71.9$ & - & $25.4 / 25.7$ & $69.4 / 63.4$ \\
CHAMPION PLATFORM [6] & $63.0 / 63.0$ & $71.9 / 70.4$ & $36.4 / 35.9$ & $31.9 / 30.3$ & $5.20 / 5.30$ \\
\hline
\end{tabular}

$C A$ cangrelor, $C L$ clopidogrel, $C A D$ coronary artery disease

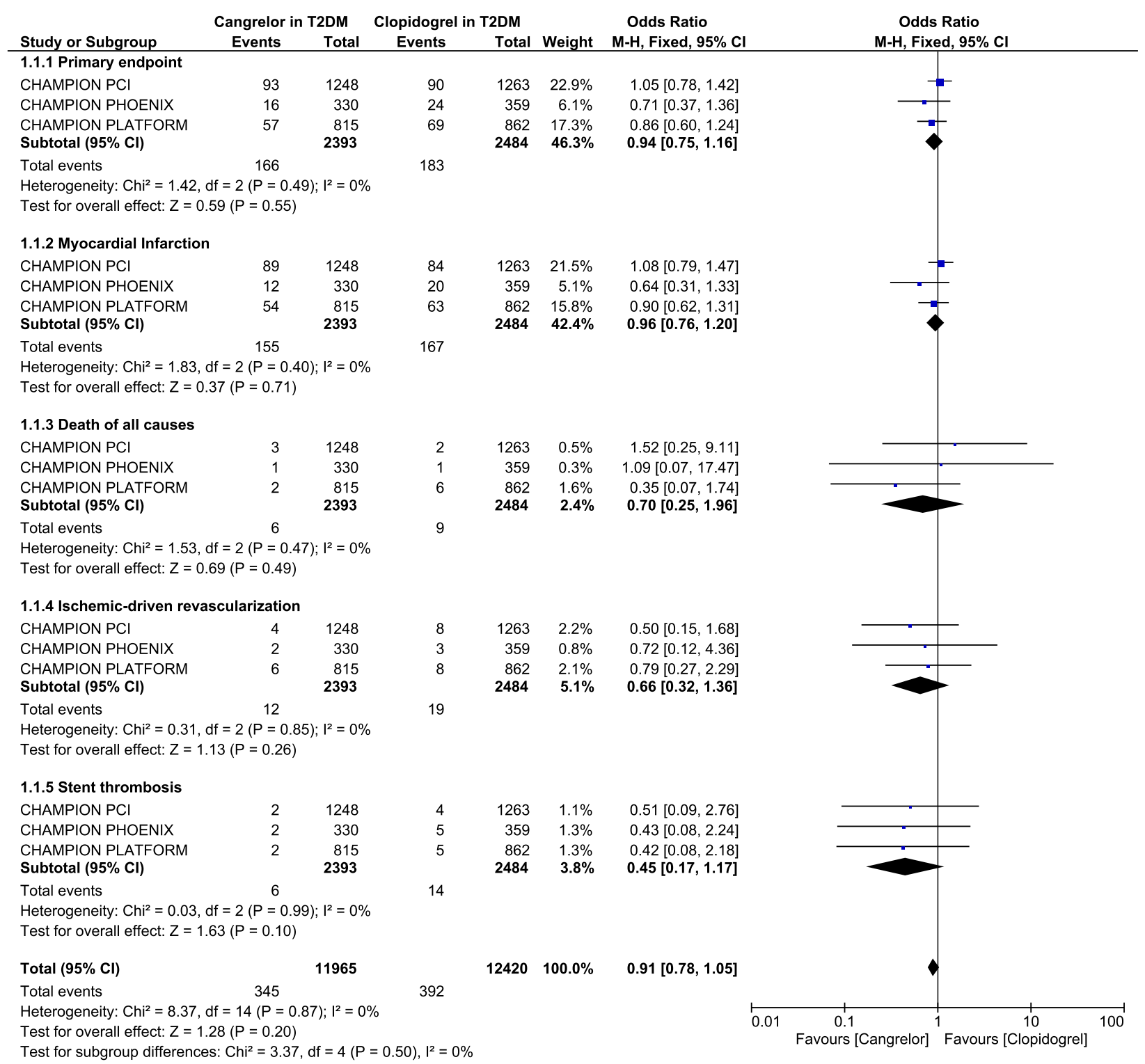

Fig. 2 Comparison between cangrelor and clopidogrel for cardiovascular outcomes 


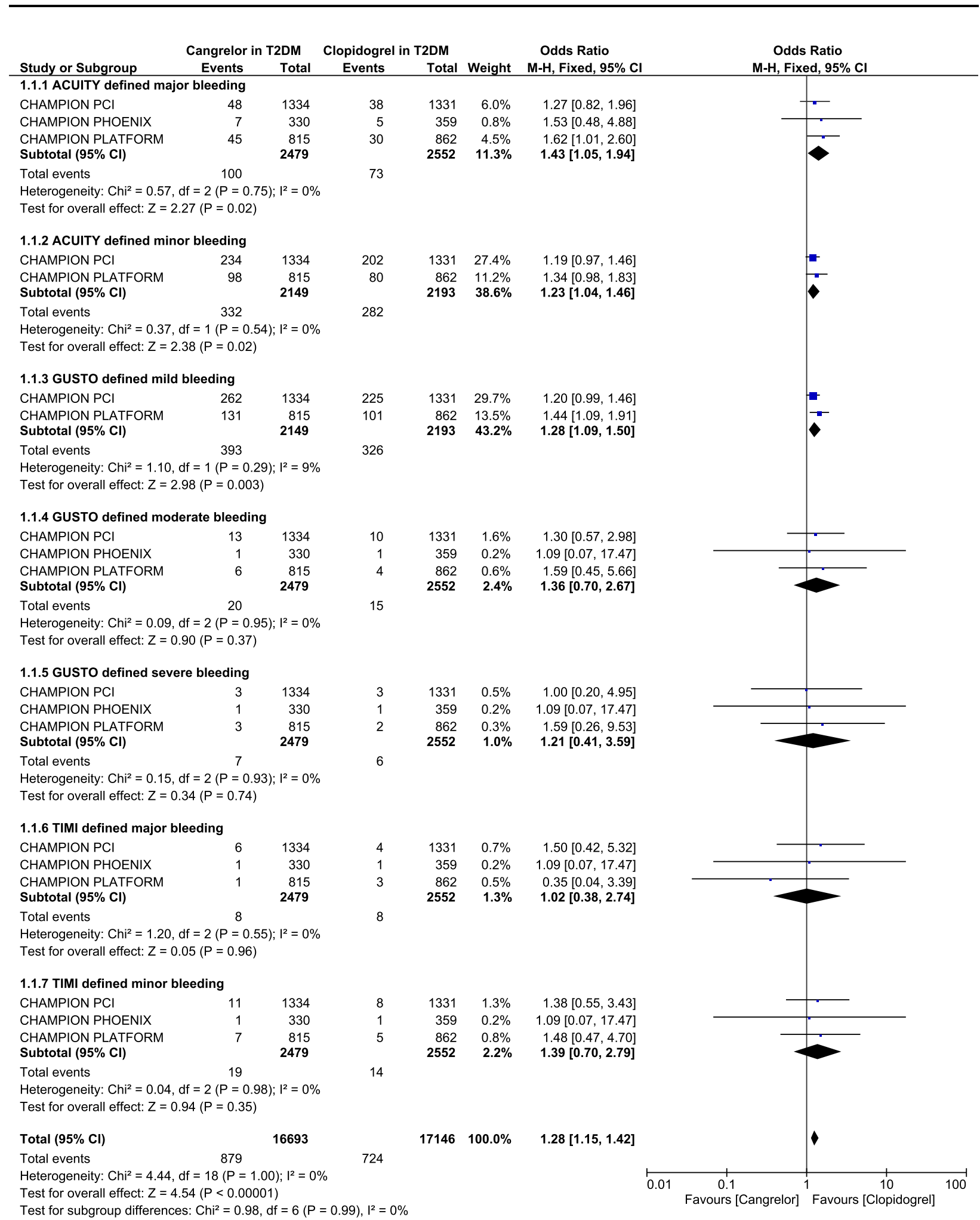

Fig. 3 Comparison between cangrelor and clopidogrel for important bleeding events 
$P=0.15$ ), thrombocytopenia (OR 1.02, 95\% CI $0.21-5.05 ; P=0.98)$, and any blood transfusion (OR 1.22, 95\% CI 0.68-2.18; $P=0.51$ ) were also assessed in these patients with T2DM, without any significant difference with either cangrelor or clopidogrel as illustrated in Fig. 4.

The results have been listed in Table 4 .

\section{Publication Bias}

Publication bias was assessed by visualizing the funnel plot as a result of the small volume of trials. A symmetrical funnel plot as shown in Fig. 5 demonstrated very low evidence of publication bias during assessment of all the clinical end points studied in this meta-analysis.

\section{DISCUSSION}

The effect of cangrelor in T2DM patients undergoing PCI has seldom been studied [10]. In this analysis, the use of cangrelor was compared to clopidogrel during PCI in patients with T2DM. The current results showed similar efficacy outcomes; however, cangrelor was associated with significantly higher GUSTO-defined mild and ACUITY-defined major and minor bleedings, whereas TIMI-defined bleedings were similar to those of clopidogrel. Other outcomes such as intracranial hemorrhage, epistaxis, access site bleeding, and hematoma were not significantly different in these patients with T2DM. However, these safety outcomes associated with bleeding events should be further studied since only three trials were available for inclusion in this analysis. Lack of data and studies might have an effect on these outcomes during analysis.

The CHAMPION PHOENIX trial showed cangrelor to improve anti-ischemic events in comparison to clopidogrel without even increasing the bleeding risk in the participants which were involved in the trial [11]. This effect was observed irrespective of the use of glycoprotein IIb/IIIa inhibitors [12]. Patients with T2DM were combined and mixed with patients without diabetes mellitus and assessed.

The CHAMPION PHOENIX trial also demonstrated cangrelor to significantly reduce the risk of stent thrombosis in the general population of patients with stable angina and acute coronary syndrome [13]. The trial also showed no influence of cangrelor on GUSTO moderate/severe bleeding when compared to clopidogrel. Our analysis also showed no influence of cangrelor on moderate/severe GUSTOdefined bleeding. However, cangrelor significantly increased GUSTO-defined mild bleeding in these patients with T2DM. In addition, our current analysis did not show cangrelor to significantly decrease stent thrombosis in these patients with T2DM. The reason behind this could be the high platelet activity or platelet dysfunction or platelet hypo-responsiveness in patients with T2DM $[14,15]$.

In a recent meta-analysis which compared the benefits of newer P2 $\mathrm{Y}_{12}$ inhibitors with that of clopidogrel and which involved about 71,097 participants, the authors concluded that newer $\mathrm{P}_{2} \mathrm{Y}_{12}$ inhibitors did decrease the risk of death post intervention; however, their safety outcomes should be further investigated [16]. In addition, a meta-analysis by Bellemain-Appaix et al. was also in favor of newer $\mathrm{P}_{2} \mathrm{Y}_{12}$ inhibitors in comparison to clopidogrel following PCI. Their analysis showed newer $\mathrm{P}_{2} \mathrm{Y}_{12}$ inhibitors to decrease mortality, and the authors stated that this result was favorable, especially in patients with STEMI [17].

Cangrelor has also shown beneficial effects when used in combination with glycoprotein IIb/IIIa, bivalirudin, and other antithrombotic agents during the invasive procedure. The use of this potential intravenous drug should be further investigated, especially in patients with T2DM.

\section{Limitations}

Limitations were associated first of all with the small sample size of patients with T2DM. In addition, longer follow-up time periods were not available for study in this analysis. Patients from the general population undergoing PCI were included in this analysis irrespective of whether they were stable or unstable angina or acute coronary syndrome participants. In addition, the duration of diabetes mellitus and the 


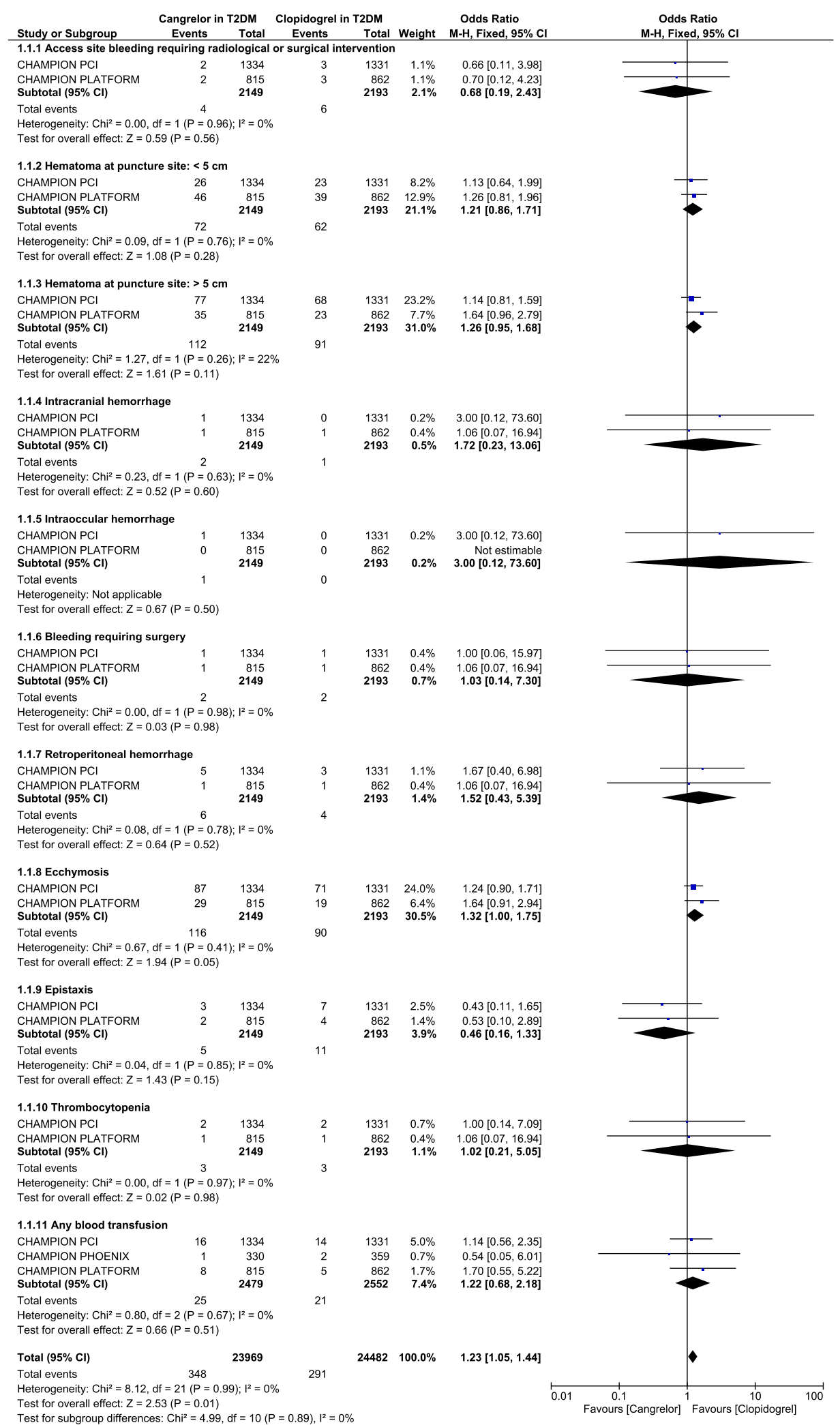

Fig. 4 Comparison between cangrelor and clopidogrel for other bleeding events 
Table 4 Results of this meta-analysis

\begin{tabular}{|c|c|c|c|}
\hline Outcomes which were assessed & OR $[95 \% \mathrm{CI}]$ & $P$ value & $I^{2}$ value $(\%)$ \\
\hline Primary end point & $0.94[0.75-1.16]$ & 0.55 & 0 \\
\hline Myocardial infarction & $0.96[0.76-1.20]$ & 0.71 & 0 \\
\hline Death of any cause & $0.70[0.25-1.96]$ & 0.49 & 0 \\
\hline Ischemia-driven revascularization & $0.66[0.32-1.36]$ & 0.26 & 0 \\
\hline Stent thrombosis & $0.45[0.17-1.17]$ & 0.10 & 0 \\
\hline Assess site bleeding requiring radiological or surgical intervention & $0.68[0.19-2.43]$ & 0.56 & 0 \\
\hline Hematoma at puncture site $\leq 5 \mathrm{~cm}$ & $1.21[0.86-1.71]$ & 0.28 & 0 \\
\hline Hematoma at puncture site $>5 \mathrm{~cm}$ & $1.26[0.95-1.68]$ & 0.11 & 22 \\
\hline Intracranial hemorrhage & $1.72[0.23-13.06]$ & 0.60 & 0 \\
\hline Intraocular hemorrhage & $3.00[0.12-73.60]$ & 0.50 & - \\
\hline Bleeding requiring surgery & $1.03[0.14-7.30]$ & 0.98 & 0 \\
\hline Retroperitoneal hemorrhage & $1.52[0.43-5.39]$ & 0.52 & 0 \\
\hline Ecchymosis & $1.32[1.00-1.75]$ & 0.05 & 0 \\
\hline Epistaxis & $0.46[0.16-1.33]$ & 0.15 & 0 \\
\hline Thrombocytopenia & $1.02[0.21-5.05]$ & 0.98 & 0 \\
\hline Any blood transfusion & $1.22[0.68-2.18]$ & 0.51 & 0 \\
\hline ACUITY-defined major bleeding & $1.43[1.05-1.94]$ & 0.02 & 0 \\
\hline ACUITY-defined minor bleeding & $1.23[1.04-1.46]$ & 0.02 & 0 \\
\hline GUSTO-defined mild bleeding & $1.28[1.09-1.50]$ & 0.003 & 9 \\
\hline GUSTO-defined moderate bleeding & $1.36[0.70-2.67]$ & 0.37 & 0 \\
\hline GUSTO-defined severe bleeding & $1.21[0.41-3.59]$ & 0.74 & 0 \\
\hline TIMI-defined major bleeding & $1.02[0.38-2.74]$ & 0.96 & 0 \\
\hline TIMI-defined minor bleeding & $1.39[0.70-2.79]$ & 0.35 & 0 \\
\hline
\end{tabular}

ACUITY acute catheterization and urgent intervention triage strategy, GUSTO global use of strategies to open occluded arteries, TIMI thrombolysis in myocardial infarction, $O R$ odds ratios, CI confidence intervals

number of participants on insulin therapy were not reported in this current analysis. Also, in the CHAMPION PLATFORM trial, the participants who were assigned to the cangrelor group also received clopidogrel as a second antiplatelet agent. This might be another limitation of this analysis. Finally, there might not have been sufficient data to assess all the required end points well. The number of trials was also low but there was nothing which could be done to improve this limitation since only three trials based on this comparison were published.

\section{CONCLUSIONS}

In these patients with T2DM, cangrelor was comparable to clopidogrel in terms of efficacy at $48 \mathrm{~h}$ following PCI. However, it was associated 

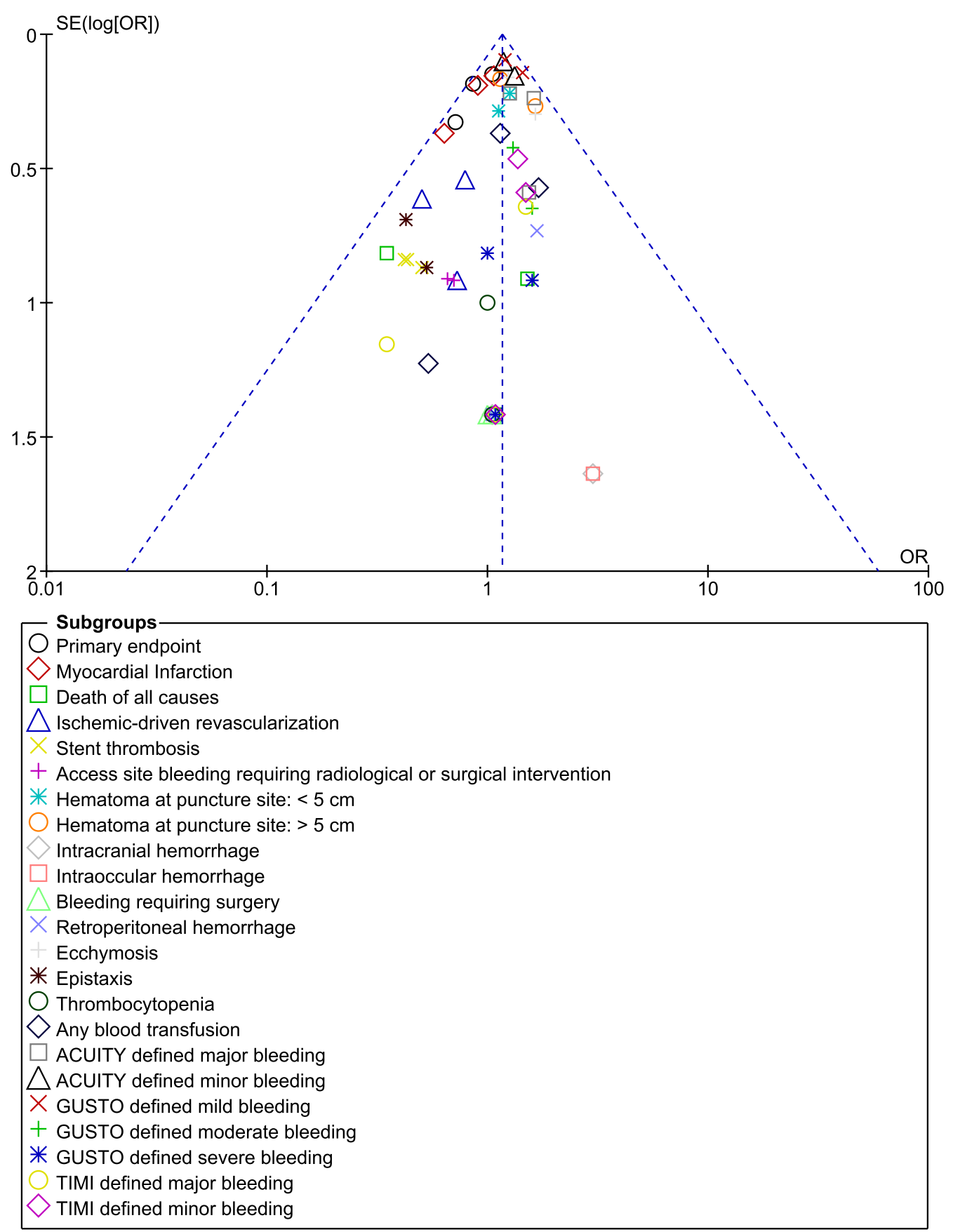

Fig. 5 Funnel plot representing publication bias

with significantly higher mild GUSTO bleeding and major and minor ACUITY bleeding, therefore requiring further workups on its safety side. This hypothesis should be explored further and confirmed in other forthcoming trials based strictly on patients with T2DM.

\section{ACKNOWLEDGEMENTS}

Funding. No funding or sponsorship was received for this study or publication of this article. 
Authorship. All named authors meet the International Committee of Medical Journal Editors (ICMJE) criteria for authorship for this article, take responsibility for the integrity of the work as a whole, and have given their approval for this version to be published.

Authorship Contributions. Hongtao Lu, Wenjun Guan, Zhangui Tang and Hong Bao were responsible for the conception and design, acquisition of data, analysis and interpretation of data, drafting the initial manuscript and revising it critically for important intellectual content. Hongtao Lu and Wenjun Guan wrote the final draft of the manuscript. Hongtao Lu, Wenjun Guan, Yanhua Zhou, Zhangui Tang and Hong Bao approved the final manuscript as it is.

Disclosures. The authors Dr Hongtao Lu, Dr Wenjun Guan, Dr Yanhua Zhou, Dr Zhangui Tang and Dr Hong Bao have nothing to disclose.

Compliance with Ethics Guidelines. This meta-analysis is based on previously conducted studies and does not contain any studies with human participants or animals performed by any of the authors.

Data Availability. All data generated or analyzed during this study are included in this published article.

Open Access. This article is distributed under the terms of the Creative Commons Attribution-NonCommercial 4.0 International License (http://creativecommons.org/licenses/ by-nc/4.0/), which permits any noncommercial use, distribution, and reproduction in any medium, provided you give appropriate credit to the original author(s) and the source, provide a link to the Creative Commons license, and indicate if changes were made.

\section{REFERENCES}

1. Zhang L, Lu J, Dong W, et al. Meta-analysis of comparison of the newer P2Y12 inhibitors (oral preparation or intravenous) to clopidogrel in patients with acute coronary syndrome. J Cardiovasc Pharmacol. 2017;69(3):147-55.

2. Alexopoulos D, Pappas C, Sfantou D, Lekakis J. Cangrelor in percutaneous coronary intervention: current status and perspectives. J Cardiovasc Pharmacol Ther. 2018;23(1):13-22.

3. Vaduganathan M, Harrington RA, Stone GW, et al. Cangrelor with and without glycoprotein IIb/IIIa inhibitors in patients undergoing percutaneous coronary intervention. J Am Coll Cardiol. 2017;69(2):176-85.

4. Harrington RA, Stone GW, McNulty S, et al. Platelet inhibition with cangrelor in patients undergoing PCI. N Engl J Med. 2009;361(24):2318-29.

5. White HD, Bhatt DL, Gibson CM, et al. Outcomes with cangrelor versus clopidogrel on a background of bivalirudin: insights from the CHAMPION PHOENIX (A clinical trial comparing cangrelor to clopidogrel standard therapy in subjects who require percutaneous coronary intervention $[\mathrm{PCI}])$. JACC Cardiovasc Interv. 2015;8(3):424-33.

6. Bhatt DL, Lincoff AM, Gibson CM, et al. Intravenous platelet blockade with cangrelor during PCI. N Engl J Med. 2009;361(24):2330-41.

7. Higgins JP, Thompson SG, Deeks JJ, Altman DG. Measuring inconsistency in meta-analyses. BMJ. 2003;327(7414):557-60.

8. Liberati A, Altman DG, Tetzlaff $\mathrm{J}$, et al. The PRISMA statement for reporting systematic reviews and meta-analyses of studies that evaluate healthcare interventions: explanation and elaboration. BMJ. 2009;339:b2700.

9. Mehran R, Rao SV, Bhatt DL, et al. Standardized bleeding definitions for cardiovascular clinical trials: a consensus report from the Bleeding Academic Research Consortium. Circulation. 2011;123(23):2736-47.

10. Ferreiro JL, Ueno M, Tello-Montoliu A, et al. Effects of cangrelor in coronary artery disease patients with and without diabetes mellitus: an in vitro pharmacodynamic investigation. J Thromb Thrombolysis. 2013;35(2):155-64.

11. Bhatt DL, Stone GW, Mahaffey $\mathrm{KW}$, et al. Effect of platelet inhibition with cangrelor during PCI on ischemic events. $\mathrm{N}$ Engl $\mathrm{J}$ Med. 2013;368(14):1303-13.

12. Vaduganathan M, Harrington RA, Stone GW, et al. Cangrelor with and without glycoprotein IIb/IIIa inhibitors in patients undergoing 
percutaneous coronary intervention. J Am Coll Cardiol. 2017;69(2):176-85.

13. Abtan J, Steg PG, Stone GW, et al. Efficacy and safety of cangrelor in preventing periprocedural complications in patients with stable angina and acute coronary syndromes undergoing percutaneous coronary intervention: the CHAMPION PHOENIX trial. JACC Cardiovasc Interv. 2016;9(18):1905-13.

14. Sobol AB, Watala $\mathrm{C}$. The role of platelets in diabetes-related vascular complications. Diabetes Res Clin Pract. 2000;50(1):1-16.

15. Yang TH, Kim DI, Kim DK, et al. Detection of clopidogrel hyporesponsiveness using a point- of-care assay and the impact of additional cilostazol administration after coronary stent implantation in diabetic patients. Korean J Intern Med. 2011;26(2):145-52.

16. Gan XD, Wei BZ, Fang D, et al. Efficacy and safety analysis of new P2Y12 inhibitors versus clopidogrel in patients with percutaneous coronary intervention: a meta-analysis. Curr Med Res Opin. 2015;31(12):2313-23.

17. Bellemain-Appaix A, Brieger D, Beygui F, et al. New P2Y12 inhibitors versus clopidogrel in percutaneous coronary intervention: a meta-analysis. J Am Coll Cardiol. 2010;56(19):1542-51. 